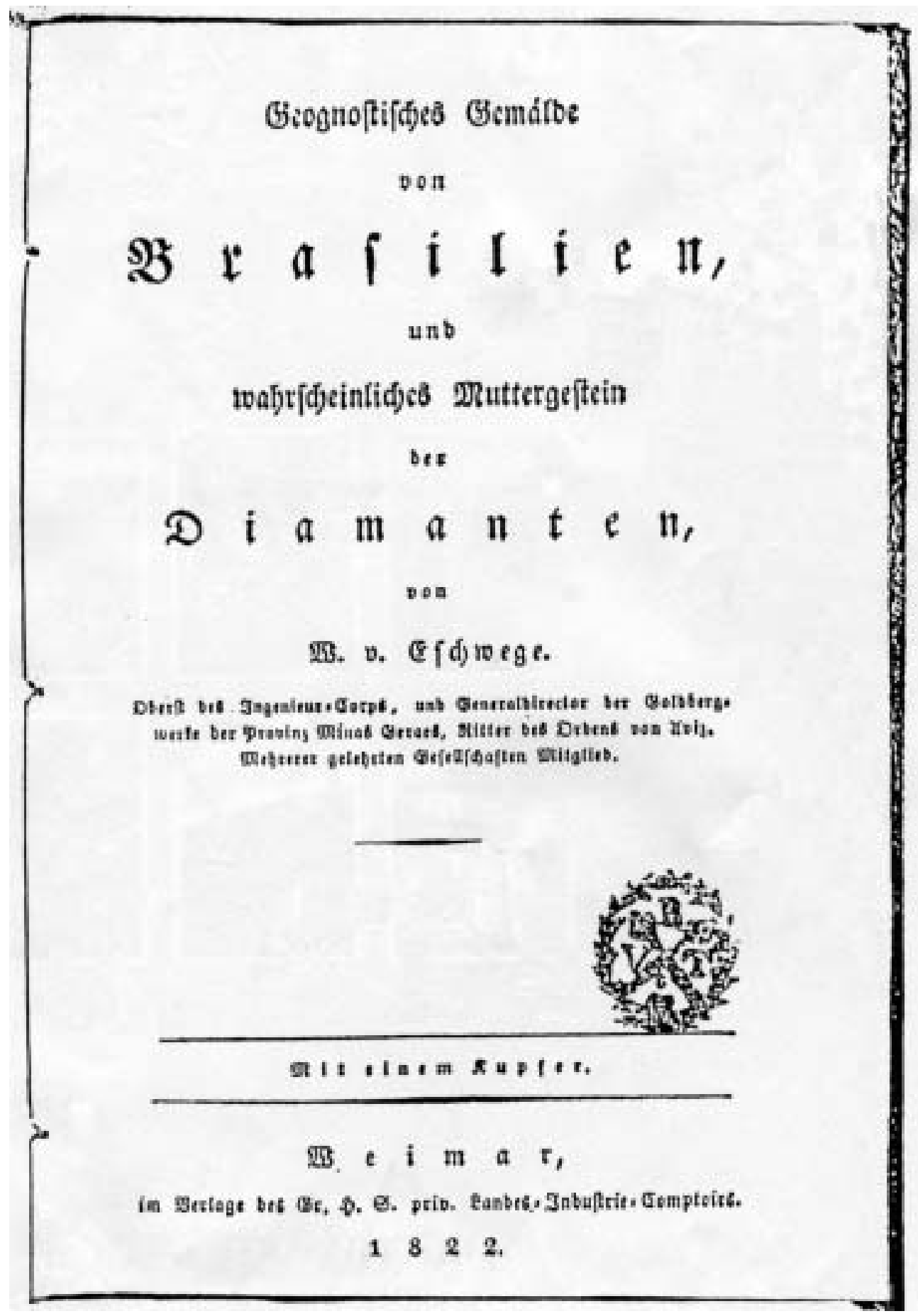




\title{
QUADRO GEOGNÓSTICO DO BRASIL E A PROVÁVEL ROCHA MATRIZ DOS DIAMANTES
}

\author{
Wilhelm von Eschwege
}

Coronel do Real Corpo dos Engenheiros e Diretor-Geral das Minas de Ouro da Província de Minas
Gerais, Cavalheiro da Ordem de Aviz, membro de várias sociedades científicas

Weimar 1822

Editora do Landes Industrie Comptoir

Tradução e notas ${ }^{1}$ de Friedrich E. Renger (Belo Horizonte 2005)

Dedicado a Sua Alteza Real, o eminentíssimo Príncipe e Senhor Carl August, Grão-Duque de SachsenWeimar-Eisenach.

Eminentíssimo Grão Duque, clementíssimo Príncipe.

Nem adulação, nem qualquer outro interesse é o motivo de colocar aos pés de sua Alteza Real o presente pequeno tratado. Somente o profundo sentimento de uma admiração, difícil de expressar, para com um Príncipe cuja fama é de geral reconhecimento e cuja verdadeira grandeza e visão de pesquisador fui feliz de conhecer e admirar de perto, deu-me a coragem de antepor a esta pequena obra um nome tão célebre para lhe ganhar um valor mais elevado. Digna-se então Sua Alteza Real de receber afavelmente esta cópia imperfeita do mundo sólido do Brasil como prova menor da minha admiração e julgar com a benevolência de que tanto necessita um nômade do Novo Mundo, que fícou fora dos círculos literários durante quase 18 anos.

Com profundo respeito sou de Sua Alteza Real seu mais obediente Autor.

Weimar, em 9 de Abril de 1822

\section{SÓ ALGUMAS PALAVRAS}

Apresso-me em oferecer ao público pátrio uma pequena obra de conteúdo geognóstico, referente ao Brasil, cujas deficiências sinto profundamente, mas que não queria reter por mais tempo, pois corrige, em parte, algumas opiniões erradas e pode oferecer a oportunidade de se tirar novas conclusões.

O descrito está sempre correto e a sinceridade e dedicação com que observei o Brasil durante onze anos, tenho certeza, não devem deixar duvidar ninguém da sua veracidade. A hipótese que apresento neste pequeno trabalho, só a ofereço como tal e espero por isso um julgamento tolerante, ainda mais que não me foi possível acompanhar os avanços das pesquisas na Alemanha. Em minhas "Notícias do Brasil"? , que serão publicadas em breve, abrir-se-á um campo mais amplo e achar-se-á uma melhor oportunidade para elucidar ao leitor alguma dúvida. Um tanto desacostumado com a língua alemã, sinto por demais a falta de uma sólida explanação que não venho a alcançar, além das dificuldades em expressar o que tenho de forma clara na minha mente.

\footnotetext{
${ }^{1}$ As notas do tradutor são marcadas por NT, pequenos acréscimos ou esclarecimentos do tradutor no texto estão entre colchetes, partes entre parênteses são do próprio autor.

${ }^{2}$ NT. Refere-se à obra Brasilien die Neue Welt, Braunschweig 1824, (2 vol.); em português: Brasil Novo Mundo, Belo Horizonte (Fundação João Pinheiro), 2 vol.; 1996 e 2001
} 


\section{PRIMEIRAPARTE}

No meu "Jornal do Brasil"3, nos "Efemérides de Moll"4 e alhures, comuniquei de vez em quando alguns assuntos geognósticos, com os quais não me sinto satisfeito. Quanto mais um geognóstico tem oportunidade de observar, tanto mais nítido ele enxerga. Durante onze anos me esforcei em dissipar as névoas que cobriam as relações das formações geológicas no Brasil e somente durante os últimos dois anos consegui, finalmente, enxergar mais claro por repetidas observações em extensas viagens, por compilações e comparações, pelo exame de muitas minas antigas e pela abertura de galerias novas nas montanhas.

O geognóstico que viaja pelo Brasil e não tem o tempo, nem a oportunidade de observar como eu, só leva a impressão geral de ter visto algo novo, porém será difícil para ele ordenar estas novidades. Orgulhome de ter adquirido uma visão geognóstica através do estudo vintenário em viagens, uma visão cuja principal particularidade consiste no fato de abranger o todo e não se deixar desviar por minúcias e creio que tal visão é necessária, não para ordenar o novo achado num sistema imaginário, mas sim, colocá-lo no devido lugar que lhe foi determinado pela natureza.

A maior parte da Europa só conhecia dos livros (nem falo da Ásia e da África, que ainda permanecem muito nas trevas, o que diz respeito a geognosia). Não achei nada que se poderia comparar com o Brasil, mas senti a necessidade de me convencer disso e uma boa oportunidade para isso, foi-me dada por uma licença. Portugal já conhecia em todas as direções de viagens anteriores, bem como uma parte da Espanha. Embarquei em Lisboa para Falmouth, a ponta mais ocidental da Inglaterra, e atravessei este belo país, indo conhecer uma grande parte da França; depois viajei na região dos rios Reno e Meno, Hesse, Saxônia, Boêmia e Áustria, até as cidades mineiras da Baixa Hungria; de lá fui visitar uma parte da Galícia [província hoje dividida entre Polônia e Rússia], Silésia, Brandenburgo até Braunschweig e através do Harz voltei a Saxônia.

Só agora tenho coragem de aparecer com confiança e apresentar uma observação fiel, bem como de esboçar algumas ligeiras idéias. Se outros naturalistas que viajaram pelo Brasil me irão apoiar deixo em aberto; pelo menos demonstrei aos senhores Dr. von Olfers ${ }^{5}$ e Dr. Pohl $^{6}$ os locais das minhas observações e parece que eles estavam convencidos.
Encontram-se no Brasil todas as camadas primárias e de transição da Europa com exceção das formações de trape [diabásio] e seqüências acamadadas ("Flözgebirgsarten") bem como formações vulcânicas, e comparando-se amostras de mão dessas formações e seus veieiros com as européias, encontrar-se-ão muitas analogias. O Prof. Weiss ${ }^{7}$ de Berlim achou-as bem semelhantes às do maciço de São Gotardo [na Suíça]. Porém, isso não prova nada. A natureza se serve das mesmas conhecidas substâncias para a composição de cada corpo individual, como, por exemplo, se utiliza do quartzo, da mica e do feldspato para fazer o granito, ou dá a minerais cristalizados a mesma forma, o que faz a hematita hexagonal do Brasil semelhante à de São Gotardo, mas fez completamente diferentes as combinações e circunstâncias e os pormenores sob os quais formam um todo, assim como os contornos ou fisionomias da superfície. Tal como um mestre-de-obras usa os mesmos materiais, madeira ou pedra de maneira distinta conforme os costumes de cada país e constrói edifícios de diferentes formas, assim também o grande mestre-de-obras da natureza trabalha no Novo Mundo com os mesmos materiais de maneira diferente do Velho Mundo. Através de uma combinação incomum de materiais bem conhecidos, como, por exemplo, da hematita lamelar ("Eisenglimmer") com quartzo, ou do talco e da clorita com quartzo resultaram grandes formações novas, desconhecidas até agora e cuja descrição é meu intento principal.

Primeiramente devo tentar esboçar para meus leitores um retrato geral do Brasil pelo que o conheço por notícias fidedignas de terceiros, mas, principalmente, através de observações próprias que abrangem as províncias do Rio de Janeiro, São Paulo, uma parte de Goiás e, principalmente, toda a província de Minas Gerais, a parte mais elevada da porção oriental do continente sul-americano, a parte onde começa o grande divisor de águas que alimenta os rios principais: o Amazonas e o da Prata.

O Brasil tem quase a forma de um coração, cujo diâmetro maior de leste para oeste começa no Cabo São Roque [Rio Grande do Norte] e estende-se em linha reta até o Peru, onde o Rio Amazonas, que tem uma extensão de cerca de 35 graus de longitude, deixa as terras dos espanhóis e entra no domínio português. Uma linha reta traçada do Cabo São Roque até a foz do Rio da Prata, que tem cerca de 30 graus de latitude, delimita esse coração pelo lado oriental, enquanto o lado

\footnotetext{
${ }^{3}$ NT. Refere-se à obra Brasilien die Neue Welt, Braunschweig 1824, (2 vol.); em português: Brasil Novo Mundo, Belo Horizonte (Fundação João Pinheiro), 2 vol.; 1996 e 2001.

${ }^{4}$ NT. Journal von Brasilien Weimar 1818 (2 vol.); em português: Jornal do Brasil, 1811-1817, Belo Horizonte(Fundação João Pinheiro), 2002.

${ }^{5}$ NT. Ignaz Franz Maria von Olfers (1793-1813), médico e naturalista, chegou ao Brasil em 1816 como médico e secretário da legação diplomática da Prússia, viajou com Eschwege no interior de Minas Gerais.

${ }^{6}$ NT. Johann Emmanuel Pohl (1782-1834), naturalista, membro da Expedição Austríaca, junto com Spix, Martius, Natterer, Thomas Ender e outros, que veio acompanhar a Princesa Leopoldina em 1817. Pohl viajou pelo interior de Minas Gerais e Goiás, hospedou-se na casa de Eschwege em Vila Rica em 1820/21.

${ }^{7}$ NT. Christian Samuel Weiss (1780-1856) mineralogista em Berlim; descreveu a coleção petrográfica do Rio Grande do Sul do naturalista Friedrich Sellow (1789-1831)
} 
ocidental passa da ponta desse coração pelos grandes rios da Prata, Paraguai e um trecho do Madeira até o Amazonas. A linha do Cabo São Roque até a foz do Rio Madeira no Amazonas pode ser considerada como limite das planícies setentrionais do Brasil, nas quais se perdem os planaltos, cadeias montanhosas e suas ramificações que se estendem de sul para norte. A linha do Cabo São Roque até a ponte mais meridional acompanha, em maior ou menor distância da costa, uma cadeia montanhosa cuja elevação média estimo, segundo diversas observações, em 3.000 pés [aprox. $1.000 \mathrm{~m}$ ]. Seus pontos mais altos têm 4.000 pés [aprox. $1330 \mathrm{~m}$ ] e é chamada em diversos locais de Serra do Mar, uma denominação apropriada que deveria ser usada para toda cadeia.

Ao atravessar esta serra do litoral encontra-se em um platô elevado que se estende de leste para oeste por todo o Brasil. Sua elevação média, segundo centenas de medições barométricas feitas por mim, é de 2.500 pés [aprox. $830 \mathrm{~m}$ ]; na sua parte ocidental desce suavemente em direção aos rios Paraguai e Madeira e depois se perde nas planícies, geralmente pantanosas, habitadas pelos índios Guaicurus que ali criam cavalos. Equivocadamente, a maioria dos geógrafos tem a opinião que a província de Mato Grosso deveria ter as montanhas mais altas, que estariam em conexão com as cordilheiras do Peru e do Chile. Não é o caso, pois se encontram amplas planícies no meio. As nascentes do Rio Madeira, que corre em direção norte para o Rio Amazonas, e do Rio Paraguai que corre para sul ao Rio da Prata, só distam uma meia hora e a elevação do divisor das águas é insignificante. Isto é evidente, mesmo para alguém que nunca visitou o lugar, pois ambos os rios são navegáveis para embarcações menores até suas nascentes. Durante o ministério do Conde da Barca ${ }^{8}$ se estudou a possibilidade de unir os dois rios através de um canal.

No planalto do Brasil levantam-se as cadeias montanhosas mais elevadas, cujos espigões atingem até 6000 pés [aprox. $2000 \mathrm{~m}$ ], com direção preferencial de norte para sul, que é também a mesma das camadas. Essas grandes cadeias distintas encontram-se, às vezes, em tais ângulos que formam uma conexão e uma serrania com a direção principal de leste para oeste. Ela começa na Serra do Mar e percorre, em grandes voltas, as províncias de Minas Gerais, Goiás e Mato Grosso, onde também se perde no planalto geral, formando assim o principal divisor de águas para norte e para sul, porque a Serra do Mar impede, à maioria dos rios, o caminho mais curto em direção ao mar para leste.

Uma dessas principais cadeias montanhosas, chamada em alguns lugares de Serra da Mantiqueira, encerra os pontos mais altos do Brasil, tais como o Pico do Itacolumi perto de Vila Rica, a Serra do Caraça junto a Catas Altas e o majestoso Pico do Itambé, perto da
Vila do Príncipe [Serro], e atravessa, pelo norte, as províncias de Minas Gerais e da Bahia seguindo até Pernambuco e para o sul, a de São Paulo até o Rio Grandedo Sul. A ela denominei Serra do Espinhaço ("Rückenknochengebirge"), não só porque forma a cordilheira mais alta, mas, além disso, é notável, especialmente para o naturalista, pois forma um importante divisor não somente sob o ponto de vista geognóstico, mas também é de maior importância pelos aspectos da flora e fauna. Do lado oriental predomina a Primeira Formação Primitiva com rochas de textura granular e xistosa: granito, gnaisse, mica xisto e sienito. Do lado ocidental ocorre a Segunda Formação Primitiva das rochas xistosas e xistosas-granulares, formação ferrífera ("Eisenstein"), ouro e formações diamantíferas, bem como as Camadas de Transição: xisto argiloso [ardósia], calcário maciço, grauvaca etc. As regiões ao leste desta cadeia, até o mar, são cobertas por matas das mais exuberantes. O lado oeste forma um terreno ondulado e apresenta morros despidos e paisagens abertas, revestidas de capim e de árvores retorcidas, ou os campos cujos vales encerram vegetação espessa apenas esporadicamente. O botânico encontra, nas matas virgens, plantas completamente diferentes daquelas dos campos e o zoólogo acha uma outra fauna, especialmente de aves, tão logo passe das matas, pela Serra do Espinhaço, para os campos.

A uma outra serrania encurvada que forma parte do divisor das águas entre o norte e o sul, e que não é propriamente dito uma serra, mas é formada pelo encontro das ramificações das serras longitudinais em ângulos diferentes, dei o nome de Serra das Vertentes ("Wasserscheidungsgebirge"). Os pontos mais proeminentes e ao mesmo tempo mais notáveis são as serras da Canastra e da Marcela, onde, de um lado, nasce o Rio São Francisco e, do outro, alguns dos principais afluentes do Rio Grande; além disso, a Serra dos Pireneus, na província de Goiás, que forma o grande divisor de águas entre o Rio Tocantins e os afluentes do Rio Paraná, e ainda, em Mato Grosso, a serrania onde se encontram as nascentes do Rio Xingu e outros ao norte e as do Rio Cuiabá ao sul.

Esse quadro sucinto da superfície do Brasil deve ser suficiente para dar aos meus leitores uma idéia elucidativa. Em seguida, darei um panorama geral das massas rochosas ou componentes desse edifício. Primeiro, devo considerar a composição do grande platô. Das regiões costeiras, que se formaram pela retirada do mar, só menciono que nelas aparece em parte a Formação Primitiva, especialmente o granito e o gnaisse, mas também muitas vezes rochas sedimentares formadas a partir da erosão do embasamento. Mais raramente se acham camadas sedimentares mais recentes, mas estas somente de distribuição restrita: o arenito de Cabo Frio, o calcário na região da Bahia, no qual se encontra madeira

\footnotetext{
${ }^{8}$ Antônio de Araújo e Azevedo (1745-1817), ministro e diplomata português, grande mecenas das ciências e artes, comprou na Alemanha a coleção mineralógica de Karl Pabst von Ohain, a qual veio com D. João VI para o Rio de Janeiro e foi, posteriormente, incorporada ao Museu Nacional.
} 
betuminosa, o calcário fétido ("Stinkstein") com peixes petrificados do Ceará e o arenito nos arredores da Fábrica de Ferro de São João de Ipanema na província de São Paulo são talvez os únicos exemplos que merecem ser mencionados.

Para o leitor poder melhor acompanhar a seqüência do meu pensamento, faz-se necessário expor aqui as minhas idéias sobre a formação das montanhas. O núcleo do Brasil que forma este platô é constituído - como no Velho Mundo - da Formação Primária, isto é, de granito e seus afiliados mais próximos. No passado, estava inclinado a admitir uma formação mais antiga e uma mais nova nessas rochas (ver o meu Jornal do Brasil, 1811 1817), porém, por observações e reflexões mais demoradas, abandonei esta idéia. Quartzo, feldspato, mica e anfibólio são os quatro principais componentes dos quais se formou este núcleo, através da cristalização, por relações químicas e precipitações e por forças de atração e daquela composição e precipitação se originou ou granito, gnaisse e mica xisto ou sienito e diabásio ou trape primordial (“Urtrapp”). As causas disso se encontram em certos pontos centrais. Se houveram vários destes pontos, onde as forças atuaram, então deve ocorrer uma repetição das rochas e, dependendo da menor ou maior atração dessas forças, desenvolveu-se um fluxo, sempre para o lado onde uma ou outra força era preponderante. Pela precipitação calma originaram-se os tipos granulares, pela mais rápida os tipos xistosos-granulares ou xistosos. Quanto mais rápida a atuação das forças, tanto mais velozes eram os fluxos e se formaram as camadas mais ou menos inclinadas e sempre para o lado da direção do fluxo principal. A estratificação das rochas torna-se vertical no caso de uma precipitação lenta de seus componentes, ou em função de forças iguais a partir de diferentes pontos centrais. As estratificações inclinaramse em virtude de uma precipitação mais rápida, ou sob a influência de forças desiguais. Quando as forças desiguais localizavam-se em pontos centrais distintos, então a direção do fluxo deveria ter sido dirigida segundo orientações diferentes. Assim, inclinações e direções deveriam também divergir, o que a observação das rochas nos permite concluir.

Creio que as elevações e depressões, que sempre me pareceram tão incompreensíveis e pelas quais se explicam direção e mergulho das camadas ou, conforme outros o querem, por apoiar-se em rochas mais antigas, adquirem com esta minha idéia maior clareza. Por exemplo, como poderia se formar no Brasil a Segunda Formação Primitiva, cujas rochas se repetem muitas vezes e cujas camadas inclinadas medem, freqüentemente, 10 milhas quando atravessadas em sua largura? Como poderiam se formar as serras principais, se não se admitisse a existência de linhas-mestre centrais, onde a afluência das rochas fosse maisintensa e cuja conseqüência natural fosse a formação de irregularidades na superfície, isto é, morros e vales?

Tanto tempo fiquei fora da Europa, que confesso estar desatualizado com relação à bibliografia mais recente, que me permitiria estar familiarizado com as melhores idéias a respeito desse assunto. Por isso peço desculpas, se apresento aqui minhas idéias que surgiram no Novo Mundo pela freqüente observação da crosta terrestre, mesmo que não se adaptem ao Velho Mundo e com isso volto ao meu assunto principal.

A Primeira Formação Primitiva de rochas no Brasil é, como já dito, de granito, gnaisse, mica xisto, sienito e rochas do trape primordial. O granito encontra-se não somente nas baixadas do litoral, como também em altitudes de 3500 pés [aprox. $1150 \mathrm{~m}$ ], juntamente com gnaisse e mica-xisto. Entretanto, em geral, estas rochas ocorrem somente nas partes mais baixas do platô. O que se observa no Velho Mundo, isto é, o granito formando os picos mais altos, em torno dos quais se agrupam os outros tipos de rochas, não ocorre no Brasil. Os mencionados três tipos de rocha ocorrem, cada um por si só, em grandes extensões ou em camadas alternadas de pequena extensão e com transições perfeitas entre si (ver Jornal do Brasil, vol. 2, p. 13/ $14)^{9}$. Sienito não se alterna com nenhum dos tipos anteriores, mas transições do gnaisse para o sienito não são raras, contudo não segundo a largura, mas sim ao longo da textura e das camadas. Parece que a solução de anfibólio foi precipitada das correntes de forma gradativa e, em seguida, carreada para cima, de modo que não poderiam se formar repetidas intercalações de sienito com outras rochas, em função das forças ascendentes que carregaram o anfibólio para níveis superiores. Formaram-se então, além do sienito, as camadas de rocha anfibolítica e de diabásio ou de trape primordial, muitas vezes formando morros ou espigões. Quando surgiam obstáculos, que impediam a ascensão das soluções do anfibólio, ocorria precipitação e uma atração, às vezes em direção contrária às camadas, às vezes paralelamente ao acamamento; formando-se assim os tão freqüentes veios e depósitos de diabásio e rocha anfibolítica, que se encontram especialmente nos arredores do Rio de Janeiro. ${ }^{10}$ Picos altos em forma de cone ou de pirâmide, que se elevam até 3800 pés [aprox. 1300 m], são característicos para os morros de gnaisse no Brasil, especialmente na Serra do Mar. Vistos à distância acredita-se que são morros de basalto. Toda esta Primeira Formação Primitiva não contém nem ouro, nem outros recursos metálicos; a grande jazida de magnetita perto de Sorocaba, na província de São Paulo, deve ser considerada uma exceção. O granito do litoral

\footnotetext{
${ }^{9}$ NT. Na tradução para o português p. 187/188: Viagem do Rio de Janeiro ao distrito de Ilha Grande.

${ }^{10}$ Nota do autor: Não se poderiam explicar os fenômenos do basalto de maneira semelhante? - NT. Esta observação refere-se certamente à discussão da época em torno da origem do basalto, se é verdadeiramente vulcânica no sentido atual, defendida pelos plutonistas ou "pseudo"-vulcânica, isto é, oriundo, através de auto-ignição, da fusão das rochas encaixantes de camadas carboníferas, propondo aqui uma solução intermediária.
} 
contém freqüentemente, como acessório, muita magnetita (ver Jornal do Brasil, Viagem à Ilha Grande); a solução de magnetita comprimiu-se mais neste local, foi precipitada e formou uma grande jazida deste mineral.

Passo agora a Segunda Formação Primitiva do Brasil, rica em ouro, que recobre a primeira na sua maior parte. Os principais componentes são: quartzo, xisto argiloso, talco em diversas formas, formações ferríferas e pouco calcário.

A combinação do quartzo com talco ${ }^{11}$ e clorita originou um novo tipo de rocha, uma novidade para o Velho Mundo, que chamei de itacolumito; formou-se também o xisto argiloso, que muitas vezes se intercala com o itacolumito, o talco e clorita-xisto e a pedra-sabão ("Topfstein"). O quartzo e a hematita formaram o especularita-xisto ("Eisenglimmerschiefer") que se comporta em relação ao itacolumito como o sienito para o gnaisse, sendo que, enquanto na Primeira Formação empurrou-se a solução de anfibólio para cima, nesta foi empurrada a possante solução de ferro. Formaram-se, como no caso do diabásio, morros altos e espigões de hematita compacta, magnetita e especularita, que descreverei sob o nome geral de itabirito. Também o talco clorita-xisto e a pedra-sabão se separaram, especialmente do xisto argiloso, e subiram mais para a superfície, formando não somente camadas, mas até morros inteiros. - O calcário em forma de mármore nem carece ser citado nessa sinopse, pois ocorre muito subordinadamente.

As cadeias montanhosas mais altas do Brasil são constituídas por esta Segunda Formação Primitiva. O Pico do Itacolumi destaca-se entre todos, pois atinge uma altitude de 6000 pés [aprox. $1980 \mathrm{~m}$; na realidade só tem $1772 \mathrm{~m}$ ], formando muitas vezes rochedos íngremes, despidos e bizarros. O xisto argiloso e o especularitaxisto não ultrapassam, provavelmente, 5000 pés [aprox. $1650 \mathrm{~m}$ ]; talco e clorita xisto afloram quase só nos vales e nas encostas, enquanto o itabirito se eleva até $5500 \mathrm{~m}$ [aprox. $1800 \mathrm{~m}$ ] e apresenta penhascos altos. O calcário primitivo ("Urkalk") encontra-se só nos lugares mais baixos, perto da Primeira Formação Primitiva. Parece ter ficado para trás, como uma matéria indolente na precipitação e empilhamento rápido das rochas, e assim foi formado só nos vales mais profundos.

Formou-se então uma Terceira Formação no Brasil, a de Transição: ardósia ("Tonschiefer"), quartzo-xisto ("gemeiner Kieselschiefer"), grauvaca ou grauvaca-xisto e calcário maciço. Encontram-se essas rochas somente no interior, para lá da grande cordilheira da Serra do Espinhaço. O xisto argiloso [ou ardósia] e o xisto silicoso se elevam até 3000 pés [aprox. $990 \mathrm{~m}$ ] e como o acamamento do primeiro é quase horizontal, eles formam amplas planícies e belas chapadas nos sertões de Minas e Goiás. Achei grauvaca nos vales profundos dos rios principais, até uma altitude de 1800 pés [aprox. $600 \mathrm{~m}$ ], enquanto o calcário, tão importante para o Brasil por causa das suas ricas grutas de salitre, eleva-se até 2845 pés [aprox. $940 \mathrm{~m}$ ]. Não considerando os morrotes de arenito, está faltando completamente a Formação Acamadada ("Flözgebirge") no interior do Brasil ou no planalto geral. Por outro lado, a Formação dos Terrenos de Aluvião tem um papel importante por causa da sua riqueza em ouro e de suas características peculiares; em parte ocorre compacta, em parte inconsolidada, não cobrindo os altos das serras, mas preenchendo os vales. À primeira pertence o conglomerado de rocha ferruginosa ("Eisensteinconglomerat"), para o qual mantenho o nome de origem local tapanhoacanga, bem como os depósitos auríferos argiloso-barrentos, com fragmentos angulosos de quartzo e formação ferrífera em certas regiões montanhosas. À última pertencem os conglomerados de quartzo compactos, em algumas regiões aglutinados por limonita ou hematita, às vezes são auríferos ou diamantíferos; eles ocorrem somente nos vales. A essa categoria pertencem também todos os depósitos de sedimentação mecânica de seixos soltos, de aluviões antigos e recentes, designados de cascalho e que, em muitas regiões, fornecem a maior riqueza de ouro e diamantes.

Passo agora à descrição dos tipos de rochas considerados novos, deixando de lado todos aqueles que, em amostra de mão, são iguais às do Velho Mundo e cujas ocorrências e relações [de contato] já mencionei.

Da Primeira Formação Primitiva só devo mencionar os grandes depósitos de rochas moles que formam grandes acumulações, até morros inteiros. Quartzo, feldspato, mica, mais raramente anfibólio e cristais de schorlita [turmalina negra] se misturam nas mesmas proporções como no granito e no gnaisse, de maneira que a única diferença entre eles é a solidez. Acamamento vertical, inclinado ou horizontal pode ser observado em alguns lugares. Essas rochas contêm pequenos veios de quartzo e buchos de caolim. Em muitos lugares são argilosas e ferruginosas, rasgadas por vales fundos [voçorocas], onde brotam muitas nascentes. $\mathrm{Na}$ província de Minas Gerais ocorrem esses depósitos em grande extensão, como por exemplo, em Cachoeira perto de Vila Rica.

Creio que se exagerou, até agora, a influência da atmosfera nas rochas. É certo que no clima nórdico, onde geadas e calor alternam tão fortemente, a influência tem que ser maior do que nos países tropicais, porém frio, calor e umidade podem atuar somente até uma certa profundidade, o que passa disso não é, com certeza, atribuível à influência da atmosfera. Parece-me muito mais provável que estas rochas e minerais não se encontram num estado de decomposição, mas sim num estado imperfeito e - se posso dizer assim - imaturo. ${ }^{12}$

O primeiro lugar entre as rochas de ampla distribuição da Segunda Formação Primitiva cabe ao itacolumito.

\footnotetext{
${ }^{11}$ NT. Eschwege confundiu, provavelmente devido à falta de métodos mais precisos, o talco com sericita ou outras micas brancas. 12 NT. Trata-se do chamado saibro, o intemperismo pode atingir dezenas de metros de profundidade, até mesmo mais de $100 \mathrm{~m}$.
} 


\section{A. Itacolumito}

\section{Constituintes}

Os constituintes principais dessa rocha são quartzo e talco ou clorita, combinados numa textura xistosa de granulação variável de grosseira a fina, conforme a predominância do talco ou da clorita (entre estes dois não há uma separação segura) e que se juntam assim como as palhetas de mica no mica xisto. Quartzo branco, granular é geralmente o mineral predominante e conferelhe a cor. Se talco ou clorita predominarem, a rocha adquire uma coloração azulada ou esverdeada.

Muitos mineralogistas que conhecem esta rocha somente de amostras de mão, especialmente o quartzito flexível que pertence a esse tipo de rocha, consideramna como mica xisto e tomam o talco e a clorita como mica. Como é sabido, ainda não existe uma separação exata entre mica, talco e clorita e existem transições entre elas, de maneira que se consegue clareza somente pela observação das rochas no afloramento. Certamente, esta rocha é diferente do mica xisto por suas condições geognósticas; também não pude observar transições entre elas. Entretanto, transições entre talco e clorita xisto são freqüentes, e observando minuciosamente como talco e clorita xisto passam de um para o outro, então a conclusão natural é que as palhetas de brilho sedoso, que também o bom olho não as identifica se é talco, clorita ou mica, mesmo quando muito esparsamente distribuídas na rocha muito quartzosa, não são de mica, mas de talco e clorita. Como mineral acessório encontra-se mica que se caracteriza por um brilho metálico.

\section{Textura}

A rocha mostra-se bem xistosa com um nítido acamamento, às vezes plano, às vezes ondulado; a xistosidade é, às vezes, espaçada, às vezes penetrativa. No primeiro caso forma grandes massas compactas como se vê no alto do Itacolumi, ou se parte em grandes placas [lajes] com espessura de até um pé. No último caso, pode-se abrir as placas em fatias de menos de $1 / 2$ linha [aprox. $1 \mathrm{~mm}$ ]. As palhetas de talco e clorita entrelaçamse e envolvem os grãos de quartzo de maneira que formam articulações e assim o quartzito flexível. ${ }^{13}$

\section{Constituintes acessórios}

Pequenos octaedros de martita, na sua maioria intemperizados, pirita, especularita, mica, e estranhamente sulfatos de ferro [flor de enxofre], que ocorrem às vezes como revestimento nas fissuras entre as camadas; estes últimos encontram-se nos arredores da real Fábrica de Ferro em Morro do Pilar (Minas Gerais).

\section{Posicionamento}

Coincide, como já mencionei, com o do xisto argiloso primitivo, do especularita xisto ("Eisenglimmerschiefer"), do talco e clorita xisto, do itabirito e do calcário primitivo.Alterna-se com o xisto argiloso em grande espessura e sobre grandes extensões com uma direção principal de norte para sul e mergulho geral para leste com um ângulo maior que $45^{\circ}$. Entretanto, o xisto argiloso parece formar sempre a primeira camada, mais perto da Primeira Formação Primitiva, conforme observações detalhadas em várias seções.

\section{Transições}

Observam-se transições do itacolumito para o xisto argiloso, talco e clorita-xisto, especularita-xisto e hematita compacta. Se ocorrem transições para o micaxisto da Primeira Formação Primitiva, isto deve ser ainda elucidado.

\section{Intercalações exóticas}

São de talco e clorita-xisto, bem como de quartzo, este muitas vezes intercrescido com pirrotita e schorlita.

\section{Intercalações subordinadas}

Encontram-se, tanto dentro do itacolumito, como entre ele e o xisto argiloso, um depósito constituído de quartzo em uma rocha negra de schorlita [turmalinito], muitas vezes misturada com arsenopirita, chamada pelos mineiros do Brasil de carvoeira. Esta substância é parcialmente friável, em parte maciça. A massa friável endurece quando exposta ao ar e na massa compacta se identifica somente a acumulação de turmalina, como no turmalinito dos veios estaníferos da Saxônia. Este depósito ocorre em espessuras de uma polegada até uma braça [aprox. $2 \mathrm{~m}$ ] e forma uma excelente jazida de ouro, a mais rica junto a Vila Rica e Mariana. Veios de quartzo auríferos, até de grande potência, também cortam com freqüência esta rocha, como se pode observar no Morro das Lajes perto de Vila Rica; pode conter arsenopirita, pirita e antimônio. Outros veios apresentam somente cianita e quartzo, como nos arredores de Congonhas do Campo na província de Minas Gerais.

\section{Morfologia das serras}

Forma montanhas ásperas, estéreis, muitas vezes com grotescos rochedos e picos altos.

\section{Ocorrência}

O itacolumito constitui as serras mais extensas e mais altas no Brasil, como a Serra do Espinhaço e a das Vertentes, que se prolonga até Mato Grosso e é igualmente formada na sua maior parte por ele. Os pontos mais altos são o Itacolumi perto de Vila Rica, a Serra do Caraça perto de Inficionado [hoje Santa Rita Durão], a Serra do Itambé perto da Vila do Príncipe [Serro], a Serra da Canastra e da Marcela perto de Bambuí, a dos Pireneus e a Serra dos Cristais na região de Paracatu.

\footnotetext{
${ }^{13}$ NT. É a dissolução do quartzo ao longo dos contatos que produz uma certa mobilidade dos grãos entre si e causa assim o efeito elástico. O mesmo fenômeno é observado também em quartzito puríssimos, entretanto ocorre somente quando a rocha era submetida ao intemperismo.
} 
Nome

Nomeei essa rocha de itacolumito por causa da serra mais alta do Brasil, do Itacolumi perto de Vila Rica, que é formado todo por ele. Não achei nenhum nome mais apropriado; o nome clorita-arenito ("Chloritsandstein"), como o chamei anteriormente, deve ser abandonado. Itacolumi é uma palavra indígena, composta de ita $=$ pedra e columi $=$ filho, porque do lado do rochedo mais elevado, íngreme e isolado, há um outro menor, também íngreme que parece ser um filho do primeiro.

O segundo tipo de rocha característica para o Brasil, embora muito extenso, porém menos possante, é o especularita xisto.

\section{B. Especularita xisto ("Eisenglimmerschiefer")}

\section{Constituintes}

Os principais minerais desta rocha são especularita ou hematita lamelar ("Eisenglimmer") e quartzo associados em uma textura xistosa granular, ocorrendo na maioria em estado friável, mas encontram-se também camadas extremamente duras. Hematita lamelar é o mineral predominante, que também determina a sua coloração, mais ou menos escura. Às vezes é finamente laminada e tanto a hematita como o quartzo ocorrem separados, de maneira que a rocha adquire um aspecto bandado de listras claras e escuras. O quartzo é geralmente friável, solto na superfície, o que lhe dá um aspecto poroso, carcomido. O quartzo ocorre também disseminado, o que confere à rocha uma aparência salpicada. Neste estado, a especularita mostra geralmente um alto brilho. Em fatias delgadas muito finas, o especularita xisto é, às vezes, flexível.

\section{Constituintes acessórios}

Octaedros de martita ocorrem disseminados ou em aglomerados, com pirita e especialmente ouro, além de talco, actinolita e cianita.

\section{Posicionamento}

Nas observações gerais acima mencionei que esta rocha é contemporânea à anterior [o itacolumito] e ao xisto argiloso, entretanto as alternâncias com o mesmo não são tão freqüentes e suas camadas não tão espessas. Onde a rocha ocorre, encosta geralmente no itacolumito, que neste caso é aurífero, embora não o seja quando se encosta ao xisto argiloso. Se esta rocha continua em profundidade segundo o mergulho até o embasamento da Primeira Formação Primitiva ou se na sua gênese ocorreu uma segregação das partículas de ferro para cima, isso deve ser esclarecido através de uma nova galeria que mandei abrir. Alguns geognósticos devem levantar dúvidas também sobre a formação contemporânea desta rocha com as vizinhas, especialmente quando virem que veios que cortam a rocha inferior não continuam nela. Entretanto, isso também é explicável, segundo a minha teoria da formação das rochas, tão logo se considere o papel importante das forças de atração e das relações químicas.

\section{Transições}

O especularita xisto passa, de um lado para um itacolumito muito quartzoso e do outro lado para especularita micácea e hematita, e dessas para um clorita xisto ou xisto argiloso negro. Esta transição é especialmente bem visível perto da Fábrica de Ferro do Morro do Pilar.

\section{Intercalações exóticas}

Encontram-se nele veios de quartzo aurífero, bem como camadas de limonita e pirolusita, de clorita xisto e talco xisto e ainda uma nova variedade de barita, recentemente descrita pelo conselheiro de minas J.C.L. Zinken ${ }^{14}$. Encontra-se também um novo mineral fibroso, até agora não descrito, em grandes massas e que está sendo estudado pelo Prof. Döbereiner ${ }^{15}$, mas cujos resultados desconheço por hora; além de belíssimos exemplares de limonita botrioidal de crescimento concêntrico e fibro-radial, que ocorrem nessas camadas de limonita. Talvez também o diamante?

\section{Morfologia das serras}

Esta rocha forma camadas de 6 a 10 braças [aprox. 12 a $20 \mathrm{~m}$ ] de espessura que se estendem sobre muitas milhas, mas não se distingue por uma forma particular. Somente quando esta rocha é explorada pelos mineiros por ser aurífera, apresenta em muitas regiões uma superfície rasgada e devastada, como se pode ver muito bem perto de Vila Rica, Mariana e Cocais, na província de Minas Gerais.

\section{Uso}

Lavado e separado o quartzo da especularita, fornece um bom ferro. Quando o especularita-xisto é duro e de xistosidade fina, partindo-se facilmente, serve também para cobertura de telhados e construção de sólidos muros de pedra seca.

\section{Ocorrência no Brasil}

Esta rocha é encontrada em muitos lugares da grande Serra do Espinhaço, como em outras serras até a província de Goiás, provavelmente também em Mato Grosso (de onde tenho alguns exemplares), pois acompanha geralmente a formação aurífera. Muitas vezes está coberta pelo conglomerado de pedra de ferro [tapanhoacanga].

\section{Nome}

Os minerais principais e sua textura xistosa granular me levaram a atribuir-lhe o nome especularita xisto.

\footnotetext{
${ }^{14}$ NT. J.C.L. Zinken (1790-1862), mineralogista alemão e conselheiro de minas em Braunschweig; editou as Nachrichten aus Portugal und dessen Colonien de Eschwege (Notícias de Portugal e suas colônias, Braunschweig 1820). Zincken batizou esta barita de grão grosso, procedente de Mariana, de Eschwegita; contem traços de Fe e talvez de Sr (p.267-270). Eschwege se refere a ela equivocadamente como escorodita, nome dado por Breithaupt em 1818 ao arseniato de ferro hidratado.

${ }^{15}$ NT. Johann Wolfgang Döbereiner (1780-1849), professor de química em Jena, destacou-se com trabalhos na área da química aplicada e é precursor do sistema periódico dos elementos.
} 


\section{Xisto argiloso ("Tonschiefer")}

Esta rocha é suficientemente conhecida, o que dispensa uma descrição delongada; também já tratei de seu posicionamento junto ao do itacolumito. Fica a mencionar aqui somente sua relação com outras rochas a ela associadas. São estes o talco-xisto, o clorita-xisto, o diabásio da Segunda Formação e a pedra-sabão. O xisto argiloso ocorre puro como rocha compacta de coloração cinza mais ou menos claro, partindo-se em placas de espessura variável ou se apresenta pouco sólido, até desagregado para um material terroso, com transições para o talco-xisto, o clorita-xisto, o diabásio e a pedra-sabão. As transições para o itacolumito e o especularita xisto já mencionei.

Como nas outras formações primitivas, onde as soluções de anfibólio subiram e cristalizaram, assim parece que as soluções de talco também foram empurradas para cima, formando as mencionadas transições. Acontece aqui também o que falei na Primeira Formação Primitiva do sienito: as transições, considerando as grandes ocorrências, não se dão pela largura ou paralelamente às camadas, mas sim ao longo delas, de maneira que apresentam um acamamento contínuo. ${ }^{16}$

A precipitação da solução de talco era, nos diversos lugares, maior ou menor e por isso formaram-se camadas mais ou menos potentes e também serras inteiras de talco e clorita xisto e de pedra-sabão, especialmente nos vales e nas encostas das serras mais altas.

Já mencionei que o xisto argiloso forma, em geral, a camada inferior da Segunda Formação Primitiva. Ocorre então normalmente em estado mole e de coloração vermelha por causa do ferro, como se pode observar na Serra da Boa Morte e na mina de Passagem perto de Mariana, província de Minas Gerais. Em outras regiões, como em Congonhas do Campo e especialmente junto à Vila da Campanha (Minas Gerais), este xisto argiloso mole é cortado por inúmeros veios e buchos de quartzo aurífero. Nessas regiões são estranhas as transições locais para diabásio. Primeiro encontram-se feldspato e anfibólio somente isolados aqui e ali. A partir de um certo ponto, esses minerais aumentam cada vez mais, pegam mais consistência e finalmente formam uma massa compacta de diabásio que forma um núcleo interno. Porém essas massas têm no máximo algumas braças de diâmetro. ${ }^{17}$

Tanto no xisto argiloso compacto como no mole ferruginoso, encontram-se, nas fissuras, óxidos de cobalto e manganês. O compacto apresenta traços de ouro somente de vez em quando.

Material mais variado para o mineralogista oferecem as ocorrências de talco-clorita xisto e pedra-sabão, formadas a partir do xisto argiloso. Não se pode traçar um limite exato entre esses três tipos de rocha, somente em poucos lugares eles são perfeitamente separados e inconfundíveis. No xisto argiloso completamente intemperizado ("Walkererde"), encontram-se, em buchos e veios, os belos topázios brasileiros amarelos, envoltos em uma caolinita endurecida ("Steinmark") e o tão raro euclásio, freqüentemente também a especularita, cristalizada em grandes plaquetas hexagonais, junto comtalco cristalizado, bem como cristal de rocha com cristais de topázio inclusos ou topázio com quartzo incrustado e ainda cianita, o que faz estas jazidas muito interessantes. A região de Vila Rica até o Capão do Lana [hoje Rodrigo Silva] fornece disso os melhores exemplos. Em outros lugares o mineralogista encontra uma rica colheita com belos exemplares de turmalina, pirita, octaedros de martita, aresenopirita aurífera e cianita. Uma rocha, passando de pedra-sabão para xisto argiloso, junto a Congonhas do Campo, fornece a bela crocoita [cromato de chumbo], cuja ocorrência descobri por um feliz acaso.

\section{Itabirito}

A grande ocorrência peculiar de minério de ferro ("Eisenstein") justifica também que o considero como uma rocha própria com o nome de itabirito.

\section{Constituintes}

Especularita, hematita, geralmente compacta, mas também foliada, às vezes magnetita e pouco quartzo ocorrem como rocha compacta, maciça ou apresentam uma textura xistosa granular.

\section{Constituintes acessórios}

Às vezes pouco ouro, talco, clorita e actinolita.

\section{Transições}

Para especularita xisto e itacolumito, limonita, mais raro para jaspilito.

\section{Posicionamento}

Esta rocha encontra-se preferencialmente sobreposta ao itacolumito, mas também sobre xisto argiloso. Ocorrendo em estado xistoso, seu acamamento coincide com a direção geral das rochas; quando em estado compacto, ela apresenta grandes maciços disformes, semelhante ao diabásio da Primeira Formação Primitiva.

\section{Propriedades magnéticas dos maciços rochosos}

Todos os maciços atuam, em maior ou menor grau, sobre a agulha magnética. $\mathrm{O}$ mais surpreendente é a polaridade alternada e sua variação em todas as faces, por exemplo, nas grandes paredes cúbicas dos rochedos de 2 em 2 , de 3 em 3 ou de 4 em 4 polegadas, tanto na direção horizontal como vertical [ver Fig. 1]. Uma tal massa rochosa cúbica pode ser comparada a um imã composto de muitos cubos de 2 a 4 polegadas de diâmetro cada. Mas é estranho que a força magnética não passe da distância do quadrado do diâmetro do cubo em cuja proximidade se coloca a agulha. Cada cubo atua isoladamente e o conjunto, em seu arranjo natural, que se pode comparar a um imã artificial composto, não

\footnotetext{
${ }^{16}$ NT. Estas transições ao longo do acamamento devem ser interpretados como variação lateral de fácies.

${ }^{17}$ NT. Parece que o autor refere-se ao intemperismo esferoidal dos metabasitos e anfibolitos.
} 
produz uma força mais intensa. Isso acontece nos rochedos cúbicos mais ou menos regulares, enquanto que nos grandes rochedos poligonais, quanto maior o número de faces, maior o número de eixos polares, que se cortam mutuamente sob os mais diversos ângulos. O mesmo fenômeno foi observado pelo Conselheiro de Minas Zinken nas amostras por mim enviadas.

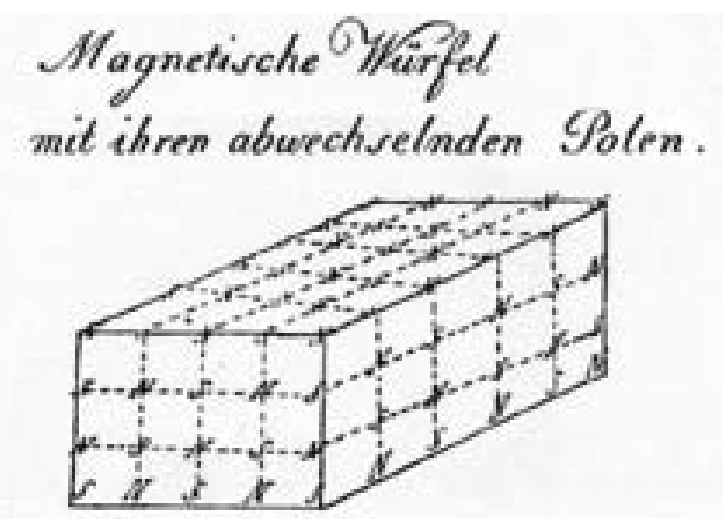

Fig. 1. Cubos magnéticos com seus pólos alternados.

\section{Ocorrência no Brasil}

$\mathrm{O}$ itabirito forma cumes e espigões altos e grotescos com muito talus no seu entorno. Destacam-se especialmente o Pico de Itabira [ou Itabirito] com uma altitude de 4895 pés [aprox. $1615 \mathrm{~m}$ ] acima do nível do mar e a Serra da Piedade perto de Sabará com 5460 pés [aprox. $1800 \mathrm{~m}$ ], ambos na província de Minas Gerais. ${ }^{18}$ Nessa última serra o itabirito atinge mais de 1000 pés [aprox. $330 \mathrm{~m}$ ] de espessura. - Dessa ocorrência tão grande pode se deduzir que, enquanto existe o mundo, ele pode ser abastecido, com toda certeza, com ferro desta região.

\section{Nome}

Tomei o nome itabirito do Morro Itabira, não longe de Sabará, que é notável tanto por sua produção de ouro como também por sua forma e altitude. Forma um rochedo bizarro, que de longe assemelha-se a uma antiga torre e que se vê a 10 milhas. Deve seu nome indígena à superfície metálica resplandecente, que produz um brilho claro, visível a grande distância; ita significa pedra, rocha e bira = claro, branco (pedra clara).

Entre as rochas da Formação de Transição não há nenhuma que mereça menção especial. Passo então para os depósitos de aluviões e aglomerados cimentados, aos quais pertence o conglomerado de pedra de ferro (“Eisensteinkonglomerat").

\section{E. Tapanhoacanga}

\section{Constituintes}

É formado por fragmentos angulosos, raramente arredondados, de especularita xisto e hematita magnética com um cimento ferruginoso de limonita vermelha ou amarela e marrom. O tamanho dos fragmentos é de algumas linhas [1 linha=aprox. $1 \mathrm{~mm}$ ] até 8 polegadas [aprox. $20 \mathrm{~cm}$ ] de diâmetro.

\section{Constituintes acessórios}

Freqüentemente é muito rica em ouro; às vezes contém palhetas de talco e clorita; também são encontrados fragmentos de itacolumito.

\section{Transições}

De vez em quando o cimento predomina tanto que os fragmentos desaparecem, dando assim origem a finas camadas de hematita compacta, geralmente com muitas palhetas de mica.

\section{Posicionamento}

O estranho posicionamento torna esta rocha especialmente notável. Encontra-se não só nos vales e nas encostas dos morros, mas cobre até os cumes mais elevados, revestindo-os até as encostas como uma crosta ou um manto, com $1 / 2$ até $1 \frac{1}{2}$ braças de espessura [1 a $3 \mathrm{~m}$ ]. Ocorre especialmente sobre especularita xisto e xisto argiloso.

\section{Camadas exóticas}

As mais notáveis nela são: camadas de limonita e a wavellita [fosfato de alumínio hidratado] que ocorre na forma de buchos nos arredores de Vila Rica.

\section{Propriedades magnéticas}

Como essa rocha é composta de inúmeros fragmentos de itabirito, tem que ser naturalmente também magnética, com os eixos polares formando os mais variados ângulos, seja numa amostra quebrada, seja na rocha inteira.

\section{Ocorrência}

A Serra de Tapanhoacanga perto de Congonhas do Campo, província de Minas Gerais, cujo cume se eleva até 4800 pés [aprox. $1580 \mathrm{~m}$ ], é toda coberta por essa rocha ao longo de algumas milhas. Toda a Serra de Vila Rica é revestida por ela, mas foi destruída pela mineração. No Campo de Saramenha, do outro lado do vale, forma um calçamento. Encontra-se ainda, freqüentemente, na estrada de Vila Rica para o Serro do Frio, cobrindo grandes distâncias. Dizem que ocorre também na província de Goiás.

\section{Nome}

Tapanhoacanga é uma palavra de uma língua africana e significa cabeça de negro. ${ }^{19} \mathrm{O}$ nome foi dado pelos mineiros devido à semelhança das crostas botrioidais com o crespo cabelo dos negros. Como é tão peculiarmente característico, mantive esse nome.

\section{Origem}

Explicar a origem deste conglomerado é uma tarefa difícil. Os fragmentos angulosos e a irregularidade com

\footnotetext{
${ }_{18}^{18}$ NT. As altitudes do Pico de Itabirito e da Serra da Piedade são 1586 m e 1746 m, respectivamente.

${ }^{19}$ NT. Na realidade origina-se do tupi-guarani: tapañu = escarvo negro, acanga = cabeça, ver também Andrade Ramos, J.R. de (1997) Tapanhun acanga. Rev. Escola de Minas (Ouro Preto), vol. 50:16-17.
} 
que são posicionados dentre a rocha, que parece formar uma cobertura dos cumes e encostas das montanhas, indicam não só uma destruição rápida dos morros de minério de ferro vizinhos, que constituem os pontos mais elevados e dos quais o Pico de Itabira, a Serra da Piedade e outros mais são vestígios. Mas uma dessecação muito rápida do fluído, que se encontrava sobre estas montanhas, carregou os fragmentos de tal forma que nem deu tempo de escorregar para dentro dos vales, ficando parados no meio das encostas, por assim dizer, como uma lava esfriada. Que esta sedimentação mecânica também não pode ocorrer pouco a pouco é bem evidenciado pela posição caótica dos fragmentos.

A origem do barro argiloso aurífero, freqüentemente com muitas braças de espessura e contendo fragmentos angulosos de quartzo e itabirito, cobrindo também morros inteiros e fornecendo belos cristais, pequenos e isolados, de ouro, é igualmente difícil de ser explicada. Também é difícil de se entender como este pode, por assim dizer, ficar colado em cima e do lado dos morros. Entretanto, não quero me demorar mais nas hipóteses sobre este fenômeno, mas passo agora para um assunto mais importante, que é a ocorrência dos diamantes.

\section{SEGUNDAPARTE}

O descobrimento dos diamantes no Brasil foi em 1727, inicialmente em alguns córregos menores do distrito do Serro do Frio, onde foram encontrados pelos negros nas lavagens de ouro e as pedrinhas reluzentes eram usadas como tentos de jogo. Só no ano seguinte chegaram como tais a Lisboa, onde foram reconhecidos e algumas leis para sua exploração foram esboçadas. Não é o meu objetivo tratar aqui da história das administrações da exploração. Limito-me somente à parte da História Natural e me refiro à parte histórica somente quando necessário.

Naqueles tempos, Portugal não tinha profissionais de ciências para a eles entregar a exploração dos diamantes ou se possuía, não se deu ao assunto a devida importância e se achava melhor um tratamento mercantilístico. Até 1772, a administração ficou nas mãos de empresas privadas. Depois continuou às custas da Fazenda Real, porém o chefe desta repartição era sempre um mero bacharel em direito. A cada três anos elegia-se um novo e os funcionários subalternos formaram-se somente na escola dos negros trabalhadores. Desta maneira, não ficamos sabendo nada sobre os aspectos científicos da ocorrência dos diamantes. Limitavam-se unicamente em saber quais eram os rios diamantíferos, sem estudar a sua origem. Satisfaziam-se com a descoberta, sem se interessar por sua formação. Vasculhavam somente os rios e deixavam as serras intocadas, pois se acreditava que os diamantes são nativos nos rios que têm suas nascentes nas encostas ocidentais da grande Serra, pertencente à Serra do Espinhaço, e se juntam em parte com o Rio Jequitinhonha, em parte com o Rio São Francisco. Criouse o Distrito Diamantino no Serro do Frio, que tem 100 milhas quadradas de superfície, e que foi ocupado com destacamentos de soldados, e todas as outras regiões do Brasil foram negligenciados.

Entretanto, como em todo lugar, existem mentes ativas e empreendedoras, movidas por ambição ou interesses, que enfrentam os maiores riscos para conseguir um determinado objetivo. Assim os recém descobertos tesouros de ouro e diamantes eram o atrativo predileto para por em movimento centenas de aventureiros, arriscando-se em desertos impenetráveis, tendo unicamente o sol como guia, dispensando todas as comodidades e vivendo somente de frutas silvestre e de caça. Foram eles que descobriram os diamantes da Serra de Santo Antônio nas Minas Novas [hoje conhecida como Serra de Grão Mogol], onde os diamantes ocorrem junto a outros seixos nos aluviões. Nos rios da margem esquerda do Rio São Francisco, tais como: Indaiá, Abaeté, Sono, Prata, Paracatu e Santo Antônio encontram-se grandes riquezas. O Rio Claro e outros na província de Goiás forneceram muitas pedras preciosas e dos rios de Mato Grosso, até a divisa com os domínios espanhóis contam-se milagres, bem como dos rios da província de São Paulo, afluentes do Rio Paraná.

O governo se viu então no embaraço de vigiar estes tesouros e impedir o contrabando. Cercou-se a Serra de Santo Antônio com guardas e ocupou-se os rios a oeste do São Francisco. Ficou proibido todo tipo de agricultura nessas regiões e foram introduzidas revistas rigorosas nas divisas da capitania. Porém deve-se ter um conceito muito pobre da inteligência humana, para não atribuí-la a capacidade de achar meios para esconder um grande tesouro de pequeno volume aos olhos vigilantes dos guardas. Por isso, houve sempre um contrabando contínuo, um comércio considerável, que estimo em dois terços dos diamantes exportados.

Com estes descobrimentos dos diamantes em grandes partes do Brasil, a ciência ganhou pelo menos alguns indícios para procurá-los em certas rochas, mas ninguém usou esses indícios. Mesmo o sábio Intendente Câmara ${ }^{20}$, que ultimamente chefiou a Administração dos Diamantes, interessou-se pouco e me manifestou sua opinião de que a formação, onde os diamantes tiveram sua origem, provavelmente não existe mais. Porém eu pesquisei mais. Nas minhas grandes viagens tive não só o a oportunidade de visitar os distritos já conhecidos, mas através de conclusões geognósticas e baseado nas minhas observações, cheguei à habilidade de encontrar diamantes onde o governo não os procurou; entretanto não eram desconhecidos aos garimpeiros, como por exemplo, nos rios Guritas, Quebra-Anzol, São Marcos e Paranaíba,

\footnotetext{
${ }^{20}$ NT. Manoel Ferreira da Câmara Bittencourt e Sá (1764-1835), mineralogista e político brasileiro, estudou em 1792/3 em Freiberg, entre 1807 e 1821 intendente da Real Administração dos Diamantes no Tejuco, encontrou com Eschwege em 1811 em Morro do Pilar; por ocasião da passagem dos naturalistas J.B. Spix e C.F. Ph. Martius em 1818 atribuiu a origem dos diamantes aos veios de quartzo.
} 
na atual divisa entre Minas e Goiás.

Baseado nas minhas muitas observações, não me restou nenhuma dúvida de que os diamantes têm sua origem na Segunda Formação Primitiva. Para afirmar com certeza se é no itacolumito, no xisto argiloso, no especularita xisto ou no itabirito, isso ainda falta investigar. Tentarei explicar as razões que me levaram a afirmar que uma dessas rochas seja a rocha matriz dos diamantes.

No distrito do Serro do Frio, onde nascem os rios diamantíferos afluentes do grande Rio Jequitinhonha, bem como os outros que correm para o Rio São Francisco, a rocha predominante é o itacolumito. Não são diamantíferos os rios que nascem na outra banda da serra, na bacia do Rio Doce, onde afloram o xisto argiloso e rochas da Primeira Formação Primitiva. Também não há diamantes em todas aquelas regiões onde predominam o xisto argiloso e o especularita-xisto, como, por exemplo, na região de Vila Rica até São João del Rei e até além do Rio São Francisco. A famosa Serra de Santo Antônio [Grão Mogol], que contem diamantes no seu espigão, é constituída predominantemente de itacolumito. Os rios diamantíferos Indaiá, Abaeté, do Sono, da Prata, de Santo Antônio e Paracatu bem como aqueles que nascem na outra encosta [da Serra das Vertentes], tais como o Rio das Velhas [hoje mais conhecido como Rio Araguari], o Quebra Anzol, Paranaíba e São Marcos têm suas nascentes nas serras formadas predominantemente de itacolumito, como, por exemplo, a Serra da Canastra e da Marcela (que juntas formam a Serra da Mata da Corda), dos Pilões, dos Pireneus e dos Cristais, serranias que pertencem todas à grande Serra das Vertentes. Segundo a informação verbal do Dr. Pohl há ainda outros rios diamantíferos que nascem em serras de itacolumito e, por isso, estou inclinado a admitir uma origem dessas pedras preciosas no próprio itacolumito. Porém a grande espessura e a ampla distribuição desta rocha são argumentos contrários a esta hipótese, pois contrastam com a raridade da ocorrência dos diamantes e a falta de um único exemplar de um diamante incrustado nesta rocha. Não consegui nenhuma informação sobre as rochas das principais serras próximas às regiões de diamantes em Mato Grosso e na província de São Paulo. Entretanto, como a mesma serrania que forma as serras da Canastra e da Marcela atravessa o Rio Grande e acompanha sua margem esquerda, seguindo o rumo para esta região, é possível que a Segunda Formação Primitiva também continue para lá.

A opinião do Intendente Câmara, de que a própria rocha matriz dos diamantes não mais existe, ganha uma certa probabilidade, pois até agora estes foram encontrados somente na superfície das montanhas, nos leitos dos rios ou, quando muito, incrustados em um conglomerado. Mas isso ainda não é uma resposta. Ao menos se deve perguntar qual era a composição desta rocha que não existe mais. Afinal, pergunto se é provável que, mesmo tendo sido destruídas as suas jazidas originais, seus vestígios podem desaparecer por completo? - Por conseguinte, o exame dos seixos dos cascalhos fornece novamente um certo indício, não só para as rochas aflorantes como também para as de outrora. Os rios diamantíferos do Distrito Diamantino do Serro do Frio, como também os da margem esquerda do Rio São Francisco e da margem direita do Rio Grande, do outro lado da Serra da Mata da Corda, eram o campo onde estudei e me deixei ensinar. Os seixos do primeiro distrito, que foram carregados diretamente das serras mais próximas, de todas as grotas e bocainas, consistem sobretudo de quartzo e itacolumito arredondados, poucos de xisto argiloso e de talco xisto, seixos de limonita, hematita, mais raro de jaspilito, calcedônia, cianita, crisoberilo, anastásio e ouro, ferro nativo em folhetas delgadas e pouca platina.

Observando os conglomerados compactos, que ocorrem em alguns vales do distrito, encontram-se fragmentos angulosos e arredondados, especialmente de quartzo com um cimento de limonita, de vez em quando com pouco jaspe e calcedônia; mais raros são diamantes e ouro. Este conglomerado é em parte grosseiro, em parte de grão fino. (Apesar de Mawe falar de uma exploração deste conglomerado por causa dos diamantes, isto não é do meu conhecimento e se ele viu talvez alguém trabalhar nesta rocha, certamente não era para extração de diamantes, e por ele não falar a língua portuguesa deixou-se enganar).

Os diamantes são distribuídos quase uniformemente nos leitos antigos como nos mais recentes, de maneira que, baseado na experiência, pode-se estimar, de forma mais ou menos exata, quantos diamantes podem ser extraídos de uma certa área. Entretanto, alguns velhos feitores me afirmaram que os leitos dos rios são em certos lugares mais ricos do que em outros: nas curvas dos rios deve-se procurar os diamantes no lado do ângulo agudo da veia d'água, também debaixo de cachoeiras. Um sinal muito bom para uma rica exploração é a freqüência de seixos de minerais de ferro existentes no cascalho. Os seixos dos rios diamantíferos da margem esquerda do Rio São Francisco, nos quais se procura diamantes, foram transportados por grandes distâncias e correram longos trechos sobre rochas da Formação de Transição. São constituídos, como os do Serro do Frio, de quartzo, pouco itacolumito, xisto argiloso, xisto silicoso, grauvaca, jaspe, limonita, uma quantidade de grãos microscópicos coloridos que são misturados com areia, bem como platina em maiores quantidades, porém nenhum ouro.

Nestes rios, a distribuição dos diamantes não é regular como no distrito do Serro do Frio; aqui se encontram longos trechos sem nenhum diamante, em outros lugares, porém, ocorrem concentrações. Dizem que uma limonita passando para jaspe é uma característica destes rios. Os rios que nascem na encosta oposta desta serra principal apresentam mais seixos de quartzo e itacolumito.

Os rios diamantíferos da província de Goiás e especialmente de Mato Grosso contêm uma quantidade extraordinária de seixos de jaspe passando para limonita.

Os aspectos mais característicos de tudo que foi dito sobre a ocorrência dos diamantes são os seguintes: 
1) a distribuição ora regular, ora irregular nos leitos dos rios antigos e recentes;

2) a maior freqüência na presença de seixos de limonita e jaspe;

3) o conglomerado com cimento de limonita com diamantes incrustados.

Durante muitos anos sabia-se de um único exemplar [do conglomerado de cimento limonítico com diamante incrustado] na coleção do Marquês de Angeja ${ }^{21}$ em Lisboa, mencionado pelo Prof. Link ${ }^{22}$ pela primeira vez. Esta mesma peça foi comprada pelo Sr. Heuland ${ }^{23}$ em Londres, onde a vi; a peça é extremamente pequena e eu confesso que dei muito pouca atenção a ela. Pareceume que a massa toda era de limonita.

Nota: Depois de ter escrito isso, recebi uma carta do Sr. Heuland, confirmando que se trata com certeza de limonita e que ele possui duas amostras com diamantes incrustados.

Um outro exemplar de um conglomerado de pequenos seixos com dois diamantes microscópicos, e que custou 900 florins, encontra-se no Gabinete de Mineralogia de Viena. Não há exemplares nas grandes coleções públicas de Londres, Paris, Rio de Janeiro e Berlim, e não tenho notícia se alguma amostra existe em coleções particulares. Por um feliz acaso obtive três exemplares. Um morador do sertão de Abaeté, que viveu durante muitos anos com os garimpeiros, presenteoume um grande pedaço de um conglomerado grosseiro, em cuja superfície apareceu um pequeno diamante. Como a amostra era muito grande, quebrei-la e fui tão feliz de encontrar numa parte três diamantes, numa outra, dois e na terceira um diamante bastante grande. Esta última amostra encontra-se agora na coleção de pedras preciosas do Grão-Duque de Weimar.

De significado maior ainda é a existência de dois exemplares nos quais encontram-se diamantes incrustados como na rocha matriz, o que confere aos primeiros uma importância ainda maior. Uma das amostras foi recebida pelo Dr. Schüch, ${ }^{24}$ bibliotecário da Princesa Leopoldina, a qual tanto o Dr. Schüch como eu identificamos como limonita. O outro exemplar está nas minhas mãos e foi visto pelo Prof. Lenz ${ }^{25}$ e outros professores de Jena. A rocha é também limonita e o diamante encontra-se numa pequena drusa de um mineral verde, que não pode ser identificado devido a seu tamanho diminuto, presumivelmente tratando-se de arseniato de ferro [escorodita]. Ambos os exemplares, tanto o da princesa como o meu, vêm do sertão do Rio São Francisco, na província de Minas Gerais, porém o local exato é desconhecido.

Como conclusão deste fenômeno, especialmente em relação ao quadro geognóstico acima, ouso afirmar que a rocha matriz dos diamantes é a própria limonita, oriunda do especularita xisto ou do itabirito, porém estou mais inclinado para o último. O seu posicionamento em forma de cumes e espigões, a sua fragmentação e a facilidade de erosão, como observado em muitas regiões, indicam isso. A opinião do Intendente Câmara tem alguma razão.

Os cumes e espigões desapareceram, as águas os levaram e os diamantes sobraram. Se a erosão dos espigões contínuos foi geral, como no caso do Distrito Diamantino do Serro, então a distribuição dos diamantes também seria regular. Se a erosão foi parcial, especialmente onde havia alguns morros isolados, a distribuição dos diamantes nos rios também seria irregular, como no distrito dos rios Indaiá e Abaeté.

Observações contínuas em toda parte desse interessante país devem levar com o tempo a um resultado seguro e confiável. Ficaria feliz se, com este breve quadro geognóstico, tiver aberto um caminho para futuros viajantes naturalistas, e através do qual eles possam chegar a seu objetivo.

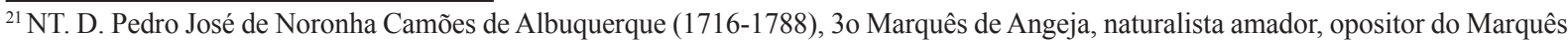
de Pombal, no reinado de D. Maria I foi ministro de estado e presidente do Real Erário, formou um notável museu particular, considerado uma atração em Lisboa.

${ }^{22}$ NT. Heinrich Friedrich Link (1767-1851), naturalista alemão, professor de botânica em Berlim, fez em 1799/1801 uma viagem de pesquisas a Portugal em companhia do Conde de Hoffmansegg.

${ }^{23}$ NT. John Henry Heuland, (1778-1856) colecionador de minerais em Londres.

${ }^{24}$ NT. Rochus (Roque) Schüch (1788-1844), naturalista austríaco, além de bibliotecário também curador das coleções de História Natural da Princesa Leopoldina, professor do jovem D. Pedro II, pioneiro da metalurgia em Minas Gerais, comprou em 1821 a Fábrica de Ferro de Timbopeba de Eschwege.

${ }^{25}$ NT. Johann Georg Lenz (1745-1832), professor de mineralogia e curador do Gabinete de Mineralogia do Grão Duque Carl August.
} 

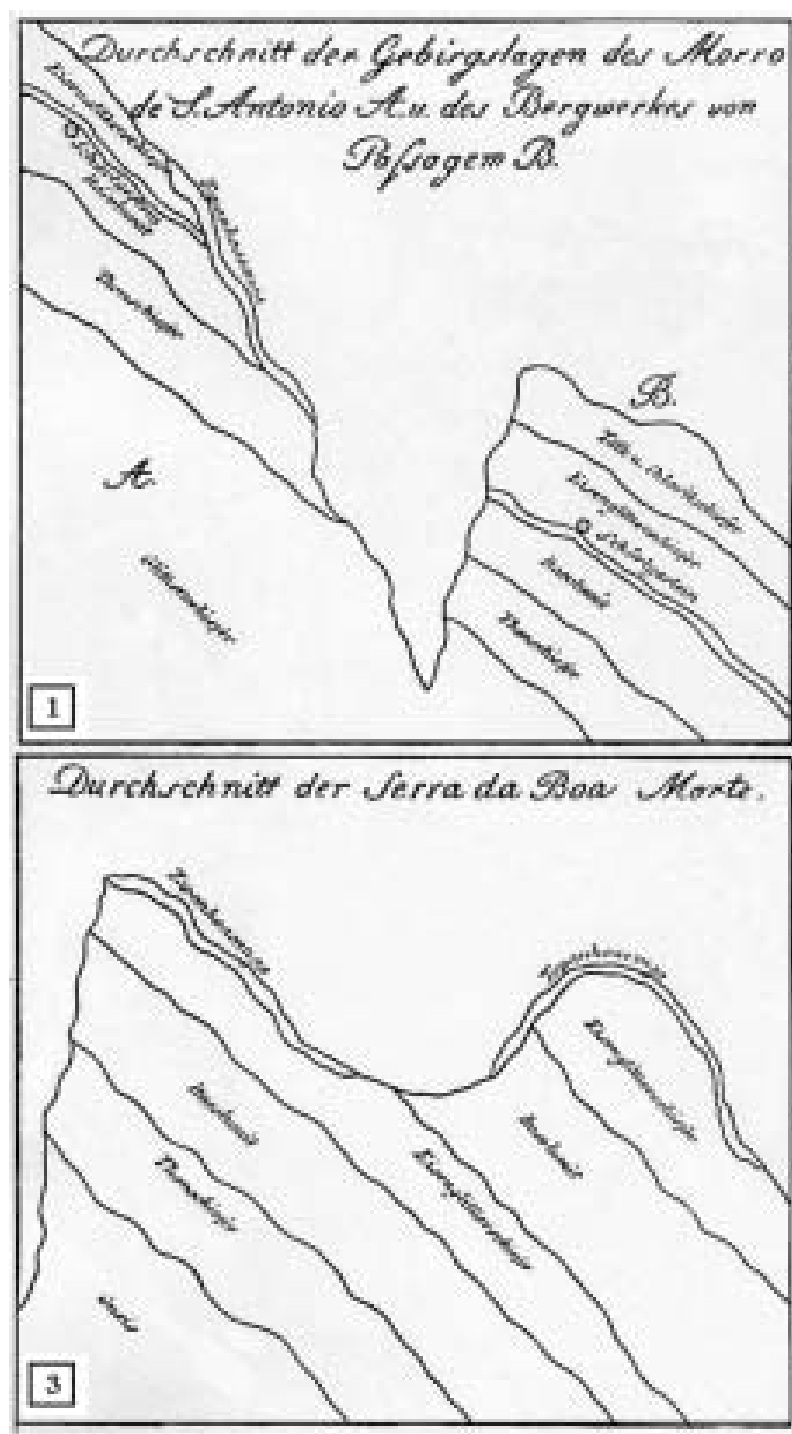

Fig. 2. Perfis geológicos no Quadrilátero Ferrífero mostrando o posicionamento das camadas

1) Perfil das camadas do Morro de Santo Antônio $(\mathcal{A})$ à mina de Passagem $(\mathscr{B})$.

2) Perfil das camadas da Serra de Vila Rica pelo vale de Antônio Dias e o Campo de Saramenha

3) Perfil da Serra da Boa Morte [perto de Congonhas do Campo]

4) Perfil da Serra de Itabirito

Legenda:

\begin{tabular}{|l|l|}
\hline Eisenglimmerschiefer & Especularita xisto \\
\hline Itacolumit & Itacolumito \\
\hline Glimmerschiefer & Mica xisto \\
\hline Gneis & Gnaisse \\
\hline
\end{tabular}

\begin{tabular}{|l|l|}
\hline Kalk & Calcário \\
\hline Schörlgestein & Turmalinito \\
\hline Talk u. Chloritschiefer & Talco e chlorita xisto \\
\hline Thonschiefer & Xisto argiloso \\
\hline
\end{tabular}

